\title{
A review of market based management as a strategic performance tool- an illustrative example through Tata steel
}

\author{
Julie Vardhan \\ Assistant Professor, School of Business, Manipal University, Dubai International Academic City, Dubai \\ E-mail: joulevardhan@gmail.com
}

\begin{abstract}
While market economy is being questioned after the recent economic crises for its philosophy of the individual working for oneself, relentless capitalism and an unaccountable profit motive; market as a construct needs to be considered in the right perspective. This study explores the concept of Market-based Management (MBM) which brings the power of a free-market economy inside a firm. Although the strategic tool had been proposed two decades back, its application to organizations as a performance tool has not been much explored. The purpose of the paper is to explore from a constructivist perspective the applicability and relevance of Marketbased Management in the context of Tata Steel, an Indian steel manufacturing company with global presence. Through secondary data analysis of Tata and at a conceptual level, it is seen that MBM could be used to transform firms into market-based institutions as a way of improving efficiency. Hopefully, the study will provide a solid ground for a more extensive research in understanding the implementation of MBM in a company.
\end{abstract}

Keywords: Austrian Economics; Constructivism; Market-Based Management; Performance Tool; Tata Steel.

\section{Introduction}

Globalization has transformed the business environment to a great extent and many of the management paradigms that were established early needs to be 'unlearned' towards creating an organization in tune with the new economy (Timothy, 2004). One of the major tenets of globalization was the ease of resource transfer across countries, the notion of maximizing reaches for more profit-features of the market. However, the market economy is being questioned after the recent economic crises for its philosophy of the individual working for oneself, relentless capitalism and an unaccountable profit motive. While the quest for a perfect system continues by researchers and policy makers, this paper posits that market as a construct needs to be considered in the right perspective. The market economy is a social system which encourages individual freedom, cooperation and rights to private property, and leads to competition and freedom of choice for the consumers. While criticism of this system abounds (Kantarcki \&Karakan, 2013), the question arises if we can concentrate on the positives of the market and reconsider the markets within firms. It is up to the organizations to acquire powerful insights by adapting elements of the market system for internal use. Market-Based Management (MBM) uses the features of a free market as a strategic tool in organisations to increase competitiveness and entrepreneurship (Cowen and Ellig, 1995). Charles Koch, the founder and CEO of Koch Industries coined the term Market Based Management, to express the company's management philosophy and practice, where MBM was successfully implemented. Koch Industries, one of the privately held petroleum companies in US, with revenue of more than US $\$ 20$ billion, was able to generate huge revenue by concentrating on a small part of the value chain rather than verti cally integrating like the oil majors (Ellig, 1996). The founder and senior managers attribute the success of the business to its principles of market economies. The management philosophy has been compiled in a book The Science of Success by Charles Koch, which combines great economic insights with the challenges of business (William, 2008).

Among the various performance measurement and management tools used by business, it is surprising why MBM has not been considered by organisations, in spite of the exemplary performance of Koch Industries. The present study is undertaken to explore the features of Market-based Management as a strategic tool in another large organization, from a geographically different part of the world than Koch Industries and to reinvent the applicability of MBM. Following this introduction, the literature on a firm as a Market is reviewed with reference to Austrian economics. In the next section, the constructivist approach is discussed as the methodology undertaken to apply the constructs of MBM. In the following section evolution and principles of MBM are discussed after which the case of Tata Steel is illustrated as a context for MBM. Next, we discuss the limits of the constructivist perspective. The last section concludes with the proposal for consideration of MBM as a strategic performance management tool. The study helps in re-inventing the market-based management as an important tool for organisations to manage their performance.

\section{The firm as a market and Austrian econom- ics}

Although the work by Coase (1937) is considered as the pillar for the theory of the firm where the firm is considered as an economic entity capable of creating wealth, it was the post- Coasian theories 
which analyzed internal organization issues, especially as a contractual entity (Foss and Klein, 2005 in Cunha, Rego, \& Vaccaro (2014). A number of research perspectives developed after the study by Coase; namely transaction cost economies (Coase (1937), Williamson (1975), Teece(1980), contractual theory and the agency theory. Analyzing these perspectives, Cunha, Rego, \& Vaccaro (2014) infer that all these perspectives have two common dimensions- one being an anthropological understanding of human beings and second, the firm as an organizational entity. Further elaborating on the normative discussions Cunha, Rego, \& Vaccaro (2014) list the following two assumptions: individuals are rational and are driven by self-interest; and the firm is formed as a contract in order to maximize the interest of the shareholders (Pfeffer 2006; Foss and Klein 2005, Williamson 1975, Friedman 1962).

The transaction cost economies which consider the firms and markets as 'alternative modes for organizing the very same transaction' (Williamson, 1991, p.4, cited by Cowen and Parker, 1997, p.45) are one of the basic areas where market approach in terms of contract are also considered for firms. The contributing authors in this school also point out the role of senior management in setting out a strategic direction for the firm, and the importance of culture and values, which effect the transaction. The role of agency theory is in identifying the role of incentives to induce employees in firms to have the same decision -making rights as owners of property do in markets. Because of information asymmetry, principalagent relationships should reflect risk-bearing costs.

To draw the basic reference points for markets in the firm based on these perspectives according to Cunha, Rego, \& Vaccaro (2014) are- first, internal competition is required as a measure to improve efficiency of the organization; hierarchy is good for the organization to coordinate people since individuals are driven by their own self- interest; and third internal activities in the firm should be coordinated in a way to ensure financial incentives for the firm. The authors point to the examples of companies like Oracle and GE following the market mechanism for decision making like emphasisng on sales and results, rewarding top performers and weeding out under performers. Although the examples may be correctly denoting the market mechanism, market is not to be limited to these but should also include - knowledge, innovation and growth.

According to Foss and Klein (2005), even though the theory of the firm was a completely neglected area in the Austrian economics, several perspectives can be considered to be the pillars for an Austrian theory of the firm. An analysis by Bylund (2011) gives an apt description of the various approaches, for although there is value in all the previous approaches, none of them seem to offer a convincing argument for the functioning of the firm in the dynamic market process (Kirzner, 1992; 1997; Lachmann, [1940] 1977). One of the features distinguishing firms from the market is regarding the allocation of resources, which cannot be a reproduction of the Coasean firm, not just because of the extent of resources allocated but also because the two are structurally different in terms of their intensity of specialization.

The firm has an important role to play in the market process. A common starting point of Austrian economics is the use of Hayek's $(1937,1945)$ analysis of the market in terms of knowledge (Bylund,2011).The Austrian economists are relatively well known for their critique of the central planning system, instead giving importance to the use of knowledge. The problem of 'dispersed knowledge' needs to be overcome by 'moving the decisionmaking authority to where the knowledge is located, instead of moving knowledge to where the decision-making authority is located' (Jensen and Meckling, 1992, cited in Ellig, 1995, p.32). The other important contribution of the Austrian economics is in terms of competition, which should be viewed as a continuous, rivalrous process of innovation and change: 'Competition not just charges price according to marginal cost, but also bring in new products and lower-cost production methods' (Ellig, 1996, p.83). The firm takes advantage of the knowledge of the entrepreneur and is structured around a purposeful direction (cf. Ioannides, 2003) by the entrepreneur who is in control of information, includ- ing its content, dissemination and recipients. The firm is the entrepreneur's solution to his knowledge problem. Reviewing the literature on the firm, Bylund (2011) considers a body of literature that is closely related to Austrian based focus on knowledge - based on the production processes, especially the use of technology(Loasby,2002; Langlois, 2002). However, invariably both branches of literature focus on one dimension- coordination- be it of the production processes, or of knowledge. The entrepreneur being the coordinator, his role becomes extremely important in the market process. According to Kirzner (1973) the entrepreneur acts as an arbitrage between the status quo and more efficient use of resources, bridging the now and the future and thus creating value. Since entrepreneurship is a phenomenon occurring both in the market and the firm, there are few studies, which merge these fields. What is established through these reviews is that the firm is the medium used by the entrepreneurs to generate profits and also in turn benefits the market because of the competition it generates: "the firm is not solely a vehicle to generate entrepreneurial profits - it also serves the market function of a pioneering benchmark for competitor entrepreneurs in terms of its novel structure of production" (Bylund, 2011, p.206).

Competition in an economy paves the way for innovation, and it also forces entrepreneurs to differently employ the resources existing in production system (Schumpeter, 1939). Schumpeter's view regarding competition forms one of the principles of Austrian economics that suggests that the hyper competition in the market as a result of globalization encourages entrepreneurship and innovation (Kiessling, 2004). Just as competition creates the change dynamics resulting in innovation, the Austrian economics emphasises the market process or market dynamics even within organizations to create what is termed as corporate entrepreneurship. Schumpeter's vision of entrepreneurship as 'creative destruction' $(1934,1942)$ is as much to be applied within organizations as it is outside. According to the Schumpterian view, entrepreneurship disrupts the market and moves it away from equilibrium, creating a cycle of innovation, disequilibrium, discovery and profits for the entrepreneur (Jacobson, 1992). This cycle can be construed to be beneficial for competition, as according to the Austrian economists, competition as a process can only happen in a dynamic environment, not in a 'perfect market'. The firm must be marketoriented internally to process information and knowledge from the external environment to be able to do so (Cowen \&Parker, 1997). Market is to be understood from the perspective as Samuels (2004) suggests, are socially constructed, neither given and transcendental nor natural but organized to promote some interests rather than others; which interests and how they are chosen and structured, are issues to be determined (p.359).

Market as construed by Samuels (2004) suggests that it is formed for the interests of some, indicating economic activity. This is resonant with the theory of the firm which undertakes economic activity for creation of wealth (Coase, 1937).

\section{The constructivist paradigm}

Austrian economics being the foundation on which MBM is based, it is quite a challenge to consider a methodology for the study. This is because many of the Austrian economists consider econometricism as inadequate for a field that involves a complex interaction among variables, with the variables dependent on human will, values and systems (Jacobson, 1992). Both Mises and Kirzner consider that the real world includes a whole range of matters beyond the scope of econometricism which can be observed, but not measured, but, which has an impact on the business performance.

Among the various perspectives in the strategy research, the study by Durand and Haara (2009), especially on the causation describes these four bases: positivism, constructivism, realism and pragmatism. While positivism is about the object and its empirical evidence, constructivism is about the construct and how the researchers understand it, realism is about the causal mechanism in specif- 
ic settings and pragmatism being about the instrumental value with a focus on the effects on action, each having their advantages and disadvantages. Among the various approaches, constructivism, therefore, is found to be most suitable to the present study. According to Highfield \& Bisman (2012), constructivism involves three important viewpoints embedded in it: knowledge is considered relativist; interpretivism is considered as the framework of exploration, and the methodology is to be hermeneutical or dialectical. Constructivism is about the 'construct' of the knowledge, rather than the object of knowledge. A number of scholars (Hine, 1988; Parker, 1998; Kincheloe, 2008) explaining the constructivist approach considered it to be a description of the social realities, and its interpretation through language, with Hine (1998) commenting, "In communicating reality. We construct reality" (p.251). Reviewing the studies of these scholars, Highfield\& Bisman (2012) propose that constructivist approach focuses on meanings found in documents, texts, archival data, narratives and stories through interviews, and the analysis. Therefore, is interpretive rather than scientific. Marsden and Littler (1996) examined the two research paradigms - positivism and constructivism with respect to marketing and consider constructivism to be more marketoriented approach as it considers the involvement of consumers in all aspects of marketing.

An inclusive approach as this seems to be appropriate for the present study and also since Highfield and Bisman (2012) mentions that it allows researchers to give meaning to things as they are; identifies factors without the use of metrics and statistics, and reports constructs as understood by the researcher. Knowledge, according to constructivism ,is time, space and context based, and in line with many of the management scholars proposing the importance of 'contextualising' research (Rousseau and Fried, 2001 in Mair, 2001),), this study attempts to study the context of MBM through the example of Tata Steel. Secondary data, mainly through company archives, the company website, and journals are analysed to understand the context of MBM. The sections that follow consist of evolution and principles of MBM and then MBM as applied in Tata Steel.

\section{Principles of MBM}

The contention of organisational economists is that their study may not provide a recipe for correct production in an organization but the economic tools definitely provide a better understanding of managerial and economic issues. As Hayek (1945) mentioned, the main economic problem in a society is about the utilization of knowledge, which is much more relevant in the present economy where knowledge is the main differentiator among businesses. The same perspective of the economic problem is taken for the firm to create Market -based Management (MBM) by applying market economies to the managerial practice (Cowen \&Parker, 1997; Ellig, 1995, 1996).According to Koch:

"Market-Based Management means internalizing the beneficial characteristics of a free-market economy, and eliminating the harmful effects of a command economy. It's difficult in practice because we can't just copy everything from the external marketwe have to adopt market principles for use inside the firm" (Cowen and Ellig, 1995, p.1).

To understand the evolution of MBM, and its main principles, an understanding of the diverse economic thought - from transaction cost economics to agency theory and finally to the Austrian economics- has provided the input to the creation of MBM.

The most important contribution to MBM is through the Austrian economics. Ellig (1996) integrates the diverse insights from organizational economics and how they have helped in the development of market based management. Table 1 summarizes the main contributing ideas of the different organizational economics theory which has helped in the development of MBM.
Table 1: Contribution of Organizational Economics towards Development of MBM

\begin{tabular}{|c|c|c|}
\hline $\begin{array}{l}\text { Organizational } \\
\text { Economics } \\
\text { Theory }\end{array}$ & Contributing Authors & $\begin{array}{l}\text { Contributing ideas to the } \\
\text { MBM }\end{array}$ \\
\hline $\begin{array}{l}\text { Transaction } \\
\text { Cost Economies }\end{array}$ & $\begin{array}{l}\text { Coase (1937),Williamson } \\
\text { (1975),Teece(1980) }\end{array}$ & $\begin{array}{l}\text { Transactions take place } \\
\text { within the firm also, } \\
\text { although guided by firms } \\
\text { values and culture }\end{array}$ \\
\hline Agency theory & $\begin{array}{l}\text { Jensen and Mekling } \\
\text { (1976), Eisenhardt (1985, } \\
\text { 1989), Brickley, Smith \& } \\
\text { Zimmermann,(1995) }\end{array}$ & $\begin{array}{l}\text { Linking the assignment } \\
\text { of decision-making rights } \\
\text { and structure of incen- } \\
\text { tives; Because of infor- } \\
\text { mation asymmetry, prin- } \\
\text { cipal-agent relationships } \\
\text { should reflect risk- } \\
\text { bearing costs }\end{array}$ \\
\hline $\begin{array}{l}\text { Evolutionary } \\
\text { Economics }\end{array}$ & $\begin{array}{l}\text { Langlois(1994), Nelson } \\
\text { and Winter(1982), Hay- } \\
\text { ek(1979) }\end{array}$ & $\begin{array}{l}\text { Organization, like econ- } \\
\text { omy, is organic; Empha- } \\
\text { sised the importance of } \\
\text { culture and values }\end{array}$ \\
\hline $\begin{array}{l}\text { Austrian Eco- } \\
\text { nomics }\end{array}$ & $\begin{array}{l}\text { Schumpeter(1942), Hay- } \\
\text { ek(1978), Kirzner(1973) }\end{array}$ & $\begin{array}{l}\text { The use of dispersed } \\
\text { knowledge to determine } \\
\text { price; and competition as } \\
\text { a continuous process of } \\
\text { innovation and change. }\end{array}$ \\
\hline
\end{tabular}

Source: Adapted from Ellig (1996)

Organizational economics, has therefore, been the building blocks on which the framework of MBM has been created. They also give important insights into the way the firms approach their mission, roles and responsibilities, and incentives.

\section{Principles of MBM and the context of Tata steel}

To support the argument by Tsui (2004) concerning international management, the field requires studies with high level of contextualization for accuracy in empirical generalizations. Extending the argument to be also applicable in strategic performance management, and to support the constructivist paradigm, the principles of MBM is illustrated through the context of a steel company. Established in 1907, Tata Steel is among the top ten global steel companies with an annual crude steel capacity of over 28 million tonnes per annum (mtpa). It is now one of the world's most geographically-diversified steel producers, with operations in 26 countries and a commercial presence in over 50 countries. The Tata Steel Group, with a turnover of US\$ 26.13 billion in FY 2011- 2012, has over 81,000 employees across five continents and is a Fortune 500 company. Established in 1907 by Mr. Jamsetji Tata - a visionary - it is Asia's first and India's largest integrated private sector steel company (Maheswari and Ganesh, 2006). Tata Steel's larger production facilities include those in India, the UK, The Netherlands, Thailand, Singapore, China and Australia. Operating companies within the Group include Tata Steel Limited (India), Tata Steel Europe Limited (formerly Corus), NatSteel, and Tata Steel Thailand (formerly Millennium Steel).

Through the evolutionary influences of organizational economics on MBM, some key similarities between market economies and organizations can be drawn as shown in Table 2.

Table 2: Six Key Systems in Market Economies and Organizations

\begin{tabular}{ll}
\hline Market Economy & Organization \\
\hline Specialization through comparative & Mission and system \\
advantage & Values and culture \\
Rules of just conduct & Roles and responsibilities \\
Property rights & Compensation and motivation \\
Market incentive & Generation and use of \\
Free flow of ideas & knowledge \\
Price System & Internal markets \\
\hline
\end{tabular}

Source: Ellig (1995) 
Each of the six principles is briefly explained and then methods and management at Tata Steel is assessed against it.

\subsection{Mission}

An organization's mission statement should be able to reflect the comparative advantage and use that knowledge to guide all decisions of the employees; 'an effective mission must be based in economic analysis of comparative advantage and specific enough to guide employee behavior' (Ellig, 1996, p.74).

Tata Steel's vision is to be the world's steel industry benchmark through the excellence of its people, its innovative approach and overall conduct. Underpinning this vision is a performance culture committed to aspiration targets, safety and social responsibility, continuous improvement, openness and transparency. Joseph (2008) describes that Tata Steel strives to combine the three elements of society - social, environmental and economic - which ensures that business is sustainable for all stakeholders. Tata Steel's approach to business has evolved from the concept that the wealth created must be continuously returned to society. However, recognizing that profitability provided the main spark for economic activity (Joseph, 2009), the company resorted to a number of measures to adapt itself successfully to the challenges of globalization. It went on a number of mergers purchasing NatSteel in Singapore and Ferrochrome Smelter in Richards Bay, KwaZuluNatal, South Africa and the Anglo-Dutch steel giant, Corus, which specialized in high-end steel products, including aircrafts and automobiles. The then Chairman Ratan Tata felt that this purchase would integrate well with the company's global strategy. The company also initiated a number of programmes on organizational development to make the company proactive and market sensitive, working towards downsizing the number of employees and setting in modernization to increase efficiency of its plants. In 2009, the quarterly earnings indicated Tata Steel's EBITDA to be higher than that of competitors such as Nippon Steel, Arcelor, POSCO, JFE, and Mittal Steel, changing its position from the $55^{\text {th }}$ to the $5^{\text {th }}$ largest steel company in the world (Joseph, 2009). The results indicate that Tata Steel is working surely towards achieving its mission.

\subsection{Values and culture}

Just as in the society 'rules of just conduct' have an influence on economic activity, so also the 'corporate culture' has an effect in organizations. 'Everybody in the organization must comprehend, carefully preserve, and live by these values' (Nobles and Redpath, 1995).

Tata is one of the most respected companies in India and the name is synonymous with trust. This has been built over the years because of its value-based, ethical and dynamic practices, and competitive performance. The statement of purpose of the Tata group to which Tata Steel belongs explicitly seeks to improve the quality of life in the communities it serves. It says: "Our heritage of returning to society what we earn evokes trust among consumers, employees, shareholders, and the community. This heritage will be continuously enriched by formalizing the high standards of behaviour expected from employees and companies" (cited by Maheshwari and Ganesh, 2006, p.83).

Some values that are expected to be held in high esteem both in societies and firms include integrity, honesty, respect for personal dignity, openness to new ideas, freedom to make mistakes and learn from them (Ellig,1995).It is found that the Tata Group has always been driven by five core values: Integrity, Understanding, Excellence, Unity and Responsibility. These values have been formally published as guiding principles for all stakeholders in the "Tata Code of conduct" since 1998. This document was aimed to guide each employee on the values, ethics, and business principles expected of them. As enumerated by Maheshwari and Ganesh (2006), the company even 'created the position of "ethics counselor" at the senior management level to ensure the code of conduct was implemented at all departments. The Tata Code of Conduct institutionalized the firm's value system. The code also ensured the need for transparency and mutually beneficial relationship with stakeholders. Two-thirds of the equity of Tata Group's holding company, Tata Sons, is held by philanthropic trusts. Over the decades, these trusts have benefited a vast range of medical, academic, social and cultural projects and institutions. Tata Steel was one of the main foundations on which this pioneering industrial group has continued to grow around the world (Tata Steel website, 2013).

'The work of the charitable trusts of the Tatas, contributions of chairmen and directors of Tata Sons towards the industrial development of the nation, goodwill of the employees and the general public over the years, aided with extensive advertisement of the Tatas has led to the creation of a very high brand value of the Tatas'( Nayak, 2010,p.12).

Tata Steel has been bestowed with the 'CII-ITC Sustainability Prize' in the 'Category A' for Large Independent Company for five times since 2006, underlining the company's ethos built on a commitment for values beyond steel (Accord Fintech, 2013).).

\subsection{Roles and responsibilities}

In a free market, property rights play a key role in both mobilizing knowledge and providing incentives. In an organization, the same principle can be applied to give employees the roles and responsibilities according to the value generated by their knowledge to the organization. Like property rights, individual rights and responsibilities need to be clearly defined- people should know what results, they are responsible for producing and have commensurate decision-making authority: 'in a market-based firm, one's ability to hire, fire, spend money, and manage assets depends on a past track record, much as a homeowner's ability to borrow money depends on a credit record' (Ellig, 1995, p.38).

While the roles and responsibilities of the different levels of management at Tata Steel cannot be elaborated here due to limitation in terms of time and direct observation, some of the studies articulate about the implementation of Balance Scorecard (Joseph, 2008) and Objectives, Goals, Strategies and Measures (OGSM) method.

The OGSM approach is common across many of the units of Tata Steel which is done to support development and deployment of strategies at all levels, with the strategy of one level becoming the objective of the level below it (Tata Steel Annual Report, 201112).

An important attribute of this method is that it encourages changeability and entrepreneurship for the future- a principle of the extraordinary management (Parker and Stacey, 2007).

\subsection{Compensation and motivation}

Proper use of incentives to improve business performance is one of the other principles of Market -based Management.

According to Nayak (2010) and reported by the company website (2012) the Tatas have been the most innovative in Indian industry with respect to labour management and employee's motivation. The wide international exposure that the Tatas have had by virtue of being in business since 1868 gave them the opportunity to adopt the best labour management practices in India. Tatas were the first to introduce several labour welfare schemes that later became standards in the Indian industry. The eight hour working per day policy introduced in 1912 was the first in the world and enforced as a law in 1938 as per the Indian Factories Act. Similarly, its policies on free medical aid, employee welfare, maternity benefits, retiring gratuity, etc. subsequently became norms in the Indian industry. 'As a result of these innovative practices, the labour force in the group companies of the Tatas have been the most loyal of all labour groups, and they contributed well to the efficiency and growth of their respective companies' (Nayak, 2010, p.14.). Considering the importance of labour relations; Tata Steel helped in establishing the Xavier Labour Relation Institute 
(XLRI) in Jamshedpur in 1949, the first management school in India.

\subsection{Generation and use of knowledge}

Knowledge has a vital role to play in firms practicing marketbased management (Hayek, 1945; Foss, 2001; Cowen and Parker, 1997). In organization, employees should have the freedom and access to relevant information and according to their knowledge, should be compensated. The sharing of knowledge within organisations should be encouraged to promote organizational learning. Tata Steel is one of the companies, which promote organizational learning through a number of management development and training programs focused on a key 'basket of competencies' vital to the short-term/long-term growth of the firm. As described by Joseph $(2009$, p.128), "Training programs were developed by employee category, (e.g. workers, supervisors, and officers) and employee life cycle, (e.g. new employee plant visits, on-the-job training, special projects, and advanced training). To cultivate a culture of innovation and knowledge management, Tata Steel employed 'learning from failure' sessions that led to new insights into processes and innovations."

The 'dispersed knowledge' or tacit knowledge as described by Hayek (1945) is also mobilized at Tata Steel, from the shop floor to the expert knowledge that is communicated across the organization through its knowledge management (KM) portal. As discussed above the value system of the Tatas also makes it obligatory for the company to provide training to the disadvantaged groups, (e.g. tribal groups, women, social and religious minorities group) and provide training for the professional and social empowerment of these groups (Joseph, 2009). In an earlier study by Joseph (2008) the implementation of the Balance Scorecard in the company is highlighted:"The learning and growth perspective focuses on adding value to this important stakeholder group through knowledge management, continuous learning, and improved quality of life, that enabled the firm to develop internal business processes to support and implement strategy" (Joseph,2008,p.147).

To implement the knowledge and learning environment Tata Steel developed the Tata Business Excellence Model (TBEM).It helped in conducting need's analysis for training in line with strategic objectives of the organization. It also conducted talent searches and incentives to highlight achievements of motivated employees to help "unleash people's potential." For example, the "Tejaswini" program focused on empowering women by training them in "non-traditional areas" such as driving mobile equipment. Some of the trainers would be from well-known industry benchmarks as Stern Stewart and Co. and the Balance Scorecard (Joseph, 2008).

\subsection{Internal markets}

The price system of the market economy helps in coordinating an individual's decision with those made by so many others in the market. In short, they summarize the information about the value of resources. As Ellig (1995) mentioned citing Hayek (1945), the price system creates efficiency in the market system. A similar system, if created within the firms to create internal markets, would prove very efficient in adding value to the firm.

Tata Steel's internal business process is again enumerated through the study of Balance scorecard implementation by Joseph (2009). Tata Steel identified several processes key to implementing a strategy. As an example 'Operations and Fulfillment' was one critical process that included several support processes. The departments were free to determine the key process requirements that were translated into key performance measures. Key performance measures (KPM) measured the effectiveness of the process that was linked to balance the scorecard. In fact, as observed by Joseph (2009), the business units developed their own scorecards to align with the scorecard of the MD, and as an example, the objective of the R\&D was to make Tata Steel an EVA-positive company, and as MD Muthuraman put 'It is the strategy that drives the research objective. $R \& D$ has a $B S C$ that is tied to the MD's BSC. It contains various strategic measures in the perspectives of finance, customer, internal business processes, people and special projects. Its performance is measured against the metric set in the BSC' (Joseph, 2009, p.125).

\section{MBM as a strategic performance tool}

The principles of MBM as enumerated through the context of Tata Steel shows how both efficiency and effectiveness can be managed, which are tools of strategic performance management. Austrian concepts which helped shape the MBM can be used by firms for creating effective strategies. The traditional economic principles that are based on reaching equilibrium condition are not applicable to business, which witnesses changes that are ever more fast-paced. In this era of continuous and radical changes, firms must adapt and respond to the changing conditions faster than the competition. Schumpeter's (1942) view of entrepreneurship as 'creative destruction' - a continuous process to break the static equilibrium condition, seems most relevant in these times. The profitable innovations of the Japanese firms, for example, are not just about major breakthroughs but also in continuous improvements.

For firms in this era, the strategy should focus on 'special knowledge and skills of its employees and the perception of its customers' (Jacobson, 1992, p.804). A similar study by Becker and Homburg(1999) aims to conceptualize market- oriented management in terms of the degree to which management systems are designed in a way so to promote the organization's orientation towards its customers and competitors. A number of other studies also highlight the benefit of applying the market-processes to the firm strategies. Palpacuer, Seignour, \& Vercher (2011) in their study analysed how the concepts of MBM were employed in the HR practices of a large firm in France. In another study (Stanfield, 2007) comments on the importance of bringing in the principles of free-market economies to the firm to encourage learning, adaptation and innovation. The study proposes the MBM to be implemented in schools of $\mathrm{UK}$ as schools directly depend on 'knowledge' as their principal means of value creation and knowledge is one of the principle tenets of MBM.

\section{Conclusion}

MBM should change the way organisations operate. As the example of Tata shows, MBM can help transform firms into marketbased institutions as a way of improving efficiency. Analyzing the Austrian economics and the success of free-markets, Timothy (2004, p.83) considers two major factors that are both inter wined and dependent upon one another: the concept of 'creative destruction' and 'the entrepreneur'. These factors would help to be able to create the comparative advantage through the use of market systems. All the principles of market-based management seem to be applicable in the processes of Tata Steel. As Ellig (1995) points out through the examples of organisations that have adapted MBM, 'spontaneous orders to improve management practices' (Ellig, 1995, p.41) helps in creating comparative advantage and being successful. Tata Steel has come a long way since its inception in 1907 to a multinational company with presence in all the major markets. Whilst zealously guarding an enviable reputation for high ethical values inculcated by the founder, Jamshedji Tata, it has developed a placid culture over the years, with a sizeable payroll and having a turnover of above Rs.50 billion per year (i.e. US $\$ 1.5$ billion), abeing the largest private sector steel company in India affirming that 'markets are not themselves efficient; they can yield efficient results' (Samuels, 2004, 358). 


\section{Limitations and future research}

While the study attempts to contextualise MBM approach through Tata Steel, the study has apparent limitations. Despite the importance of context-specific research, we accept that the study fails to capture the multiple facets of the context both qualitatively as well as quantitatively (Shapiro, Glinow, Xiao, 2007), mainly because the data is based on secondary sources. However, as mentioned earlier, the objective of this study is to explore the possibility of considering MBM as a strategic tool applying its principles in the case of Tata Steel. The study can be used to give direction to future research in the area of constructivist philosophy, which involves the risk of ontological relativism, meaning sometimes it becomes difficult to distinguish between more or less true theories or propositions (Durand and Vaara (2009). MBM as a performance tool should not only be interpreted through a constructivist view point alone, but it would be prudent to complement it with a positivist approach to get a wholesome picture of the organisation's performance. Future studies should conduct an empirical research on the principles of MBM and also be able to measure the effect of applying MBM on the performance of a company. A case study and a longitudinal research would provide better insights in understanding the implementation of MBM in a company. Another area of debate is the application of the MBM doctrine itself. According to Cunha, Rego, \& Vaccaro (2014) some of the negative consequences for organisations implementing internal market systems could be: internal competition may relate to cynical compliance to top-down orders, causing organizational rigidity; strict compliance can cause unethical behavior; organizational cultures can ignite individualistic behavior and lastly people might lose trust in their leaders and the company as an institution. As a solution, Cunha, Rego, \& Vaccaro (2014) suggest the need to reconsider the internal market and community as constituting elements of a duality so that organisations work for achieving superior performance through internal market and also work for the community through cooperation. Also as Cowen and Parker (1997) observed that while the MBM will try to bring the positive feature of the free market inside the firm, in practice, the principles would need to be adapted to be used inside the firm. Hopefully, the study will provide a solid ground for a more extensive research in the future.

\section{References}

[1] Aaron C.T. Smith, \& Graetz, F. (2006). Complexity theory and organizing form dualities. Management Decision, 44(7), 851-870. http://dx.doi.org/10.1108/00251740610680569.

[2] Annual Report, (2012). http://www.tatasteel.com/investors/annualreport-2011-12/annual-report-2011-12.pdf..Berman, S. (2013). Ideational Theorizing in the Social Sciences since ' Policy Paradigms, Social Learning, and the State'. Governance, 26(2), 217-237. http://dx.doi.org/10.1111/gove.12008

[3] Bylund, P. L. (2011). The Division of Labor and the Firm: An Austrian Attempt at Explaining the Firm in the Market. Quarterly Journal of Austrian Economics, 14(2), 188-215.

[4] Cowen, Tyler \& Jerry Ellig (1995), Market-based Management at Koch Industries: Discovery, Dissemination and Integration of Knowledge, Competitive Intelligence Review, 6 (4) 4-13.

[5] Cunha, M., Rego, A., \& Vaccaro, A. (2014). Organizations as Human Communities and Internal Markets: Searching for Duality. Journal of Business Ethics, 120(4), 441-455. Doi: 10.1007/s 10551-013-1998-2.

[6] Das, R. (1997). Defending against MNC offensives: Strategy of the large domestic firm in a newly liberalizing economy. Management Decision, 35(8), 605-618. Retrieved from http://search.proquest.com/docview/212072553?accountid=62587 http://dx.doi.org/10.1007/s10551-013-1998-2.

[7] Durand, R., \& Vaara, E. (2009). Causation, counterfactuals, and competitive advantage. Strategic Management Journal,30(12), 12451264. http://dx.doi.org/10.1108/00251749710176118.

[8] Ellig, Jerry (1995), "From Austrian Economics to Market-based Management", The Journal of Private Enterprise, XI (1), fall. http://dx.doi.org/10.1002/smj.793.
[9] Hayek, F. A. (1945). The Use of Knowledge in Society." The American Economic Review, 35(4), 519-530.

[10]Highfield, C., \& Bisman, J. E. (2012). The Road Less Travelled: An Overview and Example of Constructivist Research in Accounting. Australasian Accounting Business \& Finance Journal, 6(5), 3-22.

[11]Homburg, C., Artz, M., \& Wieseke, J. (2012). Marketing Performance Measurement Systems: Does Comprehensiveness Really Improve Performance? Journal of Marketing, 76(3), 56-77. doi:10.1509/jm.09.0487.

[12]Irwin, S. (2013). Qualitative secondary data analysis: Ethics, epistemology and context. Progress in Development Studies, 13(4), 295 306. http://dx.doi.org/10.1177/1464993413490479.

[13]Jacobson, R. (1992). The 'austrian' school of strategy. Academy of Management Review, 17(4), 782-782. Retrieved from http://search.proquest.com/docview/210964606 accountid=62587. http://dx.doi.org/10.2307/258808.

[14] Johnson, G. B., \& Wasson, J. T. (2010). THE POLITICAL ECONOMIES OF ECONOMIC LIBERALIZATION: THE ROLE OF DIFFUSION, CRISIS, AND PARTIES IN THE SHIFT TO FREE MARKET ECONOMIES. Economics, Management \& Financial Markets, 5(2), 105-124.

[15]Joseph, G. (2008). A rationale for stakeholder-based management in developing nations. Journal of Accounting \& Organizational Change 4(2), 136-161. http://dx.doi.org/10.1108/18325910810878946.

[16]Joseph, G. (2009). Mapping, Measurement and Alignment of Strategy using the Balanced Scorecard: The Tata Steel Case. Accounting Education, 18(2), 117-130. http://dx.doi.org/10.1080/09639280802436731.

[17] Kantarci, H., \& Karacan, R. (2013). The Misusage of Free Market Economy and Turkey Example. Journal Of Marketing \& Management, 4(2), 35-45.

[18] Maheshwari, S., \& Ganesh, M. P. (2006). Ethics in Organizations: The Case of Tata Steel. Vikalpa: The Journal for Decision Makers, 31(2), 75-87.

[19]Marsden, D., \& Littler, D. (1996). Evaluating Alternative Research Paradigms: A Market-Oriented Framework. Journal Of Marketing Management, 12(7), 645-655. http://dx.doi.org/10.1080/0267257X.1996.9964442.

[20]Nayak, A. (2010). Tata Sons Limited: Firm Characteristics expressed under Competition. Journal of Case Research, 1(1), 1-63.

[21]Nobles, Bill \& Judy Redpath (1995), Market-based Management: A Key to Nucor's Success, The Center for Market Processes.

[22]Parker, David \& Ralph Stacey (2007), Chaos, Management and Economics, London, Institute of Economic Affairs

[23] Samuels, W. J. (2004). Markets and Their Social Construction. Social Research, 71(2), 357-370.

[24]Shapiro, D. L., Von Glinow, M., \& Zhixing, X. (2007). Toward Polycontextually Sensitive Research Methods. Management \& Organization Review, 3(1), 129-152. http://dx.doi.org/10.1111/j.17408784.2007.00058.x.

[25] Sinkovics, R., \& Alfoldi, E. (2012). Progressive Focusing and Trustworthiness in Qualitative Research. Management International Review (MIR), 52(6), 817-845. http://dx.doi.org/10.1007/s11575-0120140-5.

[26] Stanfield, J. (2007). MARKET-BASED MANAGEMENT IN EDUCATION. Economic Affairs, 27(1), http://dx.doi.org/10.1111/j.1468-0270.2007.00719.x.

[27] Tata Steel (2012),http://www.tatasteel.com/about-us/vision.asp\#values

[28]Thompson, M. (2011). Ontological Shift or Ontological Drift? Reality Claims, Epistemological Frameworks, and Theory Generation in Organization Studies. Academy of Management Review, 36(4), 754-773. Http://Dx.Doi.Org/10.5465/Amr.2011.65554745.

[29]William, H. P. (2008) The science of success: How market-based management built the world's largest private company. Freeman, 58, 43-44. Retrieved from http://search.proquest.com/docview/196599968?accountid=62587

[30] Tata steel bestowed with CII-ITC sustainability award. (2013, Jan 16). Accord Fintech. Retrieved from http://search.proquest.com/docview/1269599761 ?accountid=62587

[More references on request] 